\title{
Outcomes of Second Look Exploration in Testicular Torsion of Children
}

\author{
Mohsen Rouzrokh ${ }^{1}$; Alireza Mirshemirani ${ }^{1,} ;$ Ahmad Khaleghnejad-Tabari ${ }^{1}$ \\ ${ }^{1}$ Pediatric Surgery Research Center, Shahid Beheshti University of Medial Sciences, Tehran, IR Iran \\ ${ }^{*}$ Corresponding author: Alireza Mirshemirani, Pediatric Surgery Research Center, Shahid Beheshti University of Medial Sciences, Tehran, IR Iran. Tel/Fax: +98-2122924488, \\ E-mail:almirshemirani@gmail.com
}

Received: July 30, 2014; Accepted: December 25, 2014

\begin{abstract}
Background: Testicular torsion(TT), or twisting of the testicle resulting in a strangulation of the blood supply, occurs in men whose tissue surrounding the testicle is not well attached to the scrotum. It is important to emphasize that testicular torsion is a medical emergency. Objectives: The aim of this study is to evaluate the second look exploration and outcomes in TT.

Patients and Methods: Seventy boys out of 124 patients underwent early exploration and 48 hours later second look exploration due to TT. All patients were checked with preoperative color-doppler ultrasonography (CDU) and intraoperative bleeding test. Data included age at admission, side of pathology, relation of TT with season of year, duration of preoperative history, degree of testicular torsion, CDU findings, and degree of bleeding; results of second look exploration, follow-up, and outcomes were analyzed.

Results: Totally 70 patients were included in this study within five years, of which mean age was $28.6 \pm 32.9$ months (range 1 to 144 ), $48 \%$ of our patients had nausea and vomiting. Preoperative CDU showed absent/weak flow in 50 (71\%) cases. Winter showed most frequently (44\%) referred cases of testicular torsion. Orchidopexy was performed in $44(63 \%)$ and orchidectomy in 26 (37\%) cases after second look exploration. Mean follow-up duration was $3.1 \pm 1.4$ years. 4 (9\%) cases in orchidopexy group developed testicular atrophy during followup, all four cases had a history of longer than 12 hours and grade II testicular bleeding test intra-operatively. Other orchidopexy patients salvaged. 26 patients, who were in grade III, underwent orchidectomy in second look exploration.

Conclusions: TT requires emergency attention. The ischemia time of the testis is traditionally after 6 hours, and imaging or other diagnostic modality should not be a cause of delay. Early surgical exploration is modality of choice, and second look exploration after 48 hours can be more effective and salvageable in these patients.
\end{abstract}

Keywords: Spermatic Cord Torsion; Second Look Exploration; Outcomes; Child

\section{Background}

Testicular torsion occurs when a testis twists the spermatic cord resulting in cutting off of blood supply. TT implies obstruction of first venous, and later, arterial flow. The extension of testicular ischemia depends on the degree of twisting (180 - 720) and duration of the torsion. Testicular salvage mostly happens in those who are treated within 4 - 6 hours after the onset of torsion. TT accounts for at least up to $26 \%$ of cases of acute scrotum (1), but Beni-Israel et al. reported it even from $17-72 \%$ (2). Anatomically there are two types of testicular torsion which occur in different age groups:1) Extra-vaginal (supra-vaginal): torsion occurs at the level of the external inguinal ring, which is seen in neonates. 2) Intra-vaginal: a more common variety due to bell clapper deformity that typically occurs in adolescents and young adults. Typically, sudden onset of severe pain followed by inguinal/scrotal swelling and nausea or vomiting is the most common symptom of TT (2-5).

CDU and high-resolution ultrasonography are the modality of choice for diagnosis of scrotal disorders in children, and near infrared spectroscopy is a novel diagnostic approach $(1,6,7)$. Early surgical exploration is recommended by most authors in acute scrotum to prevent or confirm torsion $(8,9)$. When the diagnosis of TT is established, the surgeon faces another dilemma, i.e. whether or not to remove the testis; here only surgical exploration can make the decision. There are no definite objective criteria to assess testicular viability. There are many studies about TT but no experience in second look exploration to be compared with.

\section{Objectives}

In recent study we have performed combination of early exploration, and second-look operation only in our 70 cases.

\section{Patients and Methods}

In a historical cohort study 70 boys out of 124 patients underwent early exploration and 48 hours later second look exploration due to TT in Mofid children's hospital from January 2008 to December 2013. Fifty four cases of TT which were explored in one stage only, and neonatal torsions were excluded from the study. After color-doppler ultraso- 
nography (CDU) and necessary lab tests, emergency surgical exploration was performed in included 70 cases and after intraoperative bleeding test, this group of patients underwent second look exploration after 48 hours.

Evaluation of bleeding test: when tunica albuginea is incised, the onset of active arterial bleeding (bright blood) from the cut edge: Grade I: immediate bleeding after incision. Grade II: delayed bleeding before 10 minutes. Grade III: bleeding is absent after 10 minutes (10).

All patients were followed-up, and checked by High-resolution ultrasonography and CDU every 3 months. Data included age at admission, side of pathology, relation of TT with season of year, duration of preoperative history, degree of testicular torsion, CDU findings, and degree of bleeding, results of second look exploration, follow-up, and outcomes were analyzed, and descriptive statistical analysis was performed by SPSS 16 software.

\section{Results}

Totally 70 patients were included in this study within five years, with a mean age of $28.6 \pm 32.9$ (range 1 to 144 ) months, $48 \%$ of our patients had nausea and vomiting. Preoperative CDU showed weak flow in 50 (71.4\%) cases. Most frequently (44\%) referred cases of testicular torsion occurred in winter. Orchidopexy was performed in 44 (63\%) and orchidectomy in 26 (37\%) cases after second look exploration. Table 1 shows the duration of symptoms before surgery, intraoperative arterial bleeding test of patients in first exploration and degree of torsion in our cases. Salvageability was independent of the degree of torsion. Mean follow-up lasted $3.1 \pm 1.4$ years. 4 cases (9\%) in orchidopexy group developed testicular atrophy during follow-up; of these, blood flow was absent in one (25\%) and weak in the other (75\%) on preoperative CDU. All four cases had a history of longer than 12 hours and grade II testicular bleeding test intra-operatively. Other orchidopexy patients were salvaged. 26 patients, who were in grade III, underwent orchidectomy in second look exploration. Cold season, degree higher than $360^{\circ}$ and a history longer than 12 hour were not specific signs of testicular non-viability. Sensitivity, specificity, PPV and NPV of variables are shown in Table 2.

\begin{tabular}{|c|c|c|c|}
\hline Parameters & Orchidectomy $(n=26)$ & Orchidopexy $(n=44)$ & PValue \\
\hline Duration of symptoms before surgery, h & & & 0.599 \\
\hline$<6$ & $6(23.1)$ & $16(364)$ & \\
\hline $6-12$ & $11(42.3)$ & $13(29.5)$ & \\
\hline $12-24$ & $5(19.2)$ & $7(15.9)$ & \\
\hline$>24$ & $4(15.4)$ & $8(18.2)$ & \\
\hline Intraoperative arterial bleeding test & & & $<0.001$ \\
\hline Grade I & $0(0)$ & $20(45.5)$ & \\
\hline Grade II & $0(0)$ & $24(54.5)$ & \\
\hline Grade III & $26(100)$ & $0(0)$ & \\
\hline Degree of torsion & & & 0.377 \\
\hline $0-180$ & $4(15.4)$ & $5(11.4)$ & \\
\hline $181-360$ & $11(42.3)$ & $28(63.6)$ & \\
\hline $361-540$ & $9(34.6)$ & $9(20.5)$ & \\
\hline $541-720$ & $2(7.7)$ & $2(4.5)$ & \\
\hline Season & & & 0.172 \\
\hline Spring & $3(11.5)$ & $9(20.5)$ & \\
\hline Summer & $4(15.4)$ & $1(2.3)$ & \\
\hline Autumn & $7(26.9)$ & $15(34.1)$ & \\
\hline Winter & $12(46.2)$ & $19(43.2)$ & \\
\hline
\end{tabular}

\footnotetext{
${ }^{\mathrm{a}}$ Values are presented as No(\%).
}

\begin{tabular}{|c|c|c|c|c|c|c|c|}
\hline & Orchidectomy $(n=26)$ & Orchidopexy $(n=44)$ & P Value & Sensitivity & Specificity & PPV & NPV \\
\hline History $>12 \mathrm{~h}$ & $9(34.6)$ & $15(34.1)$ & 1.0 & 34.1 & 65.4 & 62.5 & 37 \\
\hline Degree $>360$ & $19(73.1)$ & $27(61.4)$ & 0.436 & 61.4 & 26.9 & 58.7 & 29.2 \\
\hline Cold Seasons & $19(73.1)$ & $34(77.3)$ & 0.776 & 77.3 & 26.9 & 64.1 & 41.2 \\
\hline Grade III & $26(100)$ & $0(0)$ & $<0.001$ & - & - & - & - \\
\hline
\end{tabular}

\footnotetext{
${ }^{\mathrm{a}}$ Values are presented as No (\%) or \%.
} 


\section{Discussion}

TT torsion is an emergency condition with risk of irreversible ischemic injury if not promptly treated. It is caused by the torsion of the spermatic cord within the space of the tunica vaginalis in children and adolescents. It may result due to lack of normal fixation of testis or epididymis to the facial and muscular layers of cord or scrotum. TT accounts for only about $20-25 \%$ of all cases of acute scrotum in children (11). Boettcher et al. (12) reported 19 TT with median age of 10 (range 0 - 15) years, in our research mean age was 28 (range 1 - 144) months. The most common symptoms in TT are swelling/erythema, nausea and vomiting. Incidence of nausea and vomiting in our study was $48 \%$, and in Mellick (13) it was $32 \%$. The incidence of TT is more common in left side, as it was $74 \%$ in our patients, and 63\% in Boettcher et al. (12) study. Duration of symptoms before surgery is an important predictor of outcome in TT (14). Jefferson et al. (15) reported that no testicle with a history longer than 12 hours could be salvaged. Other researchers (11) observed testicular necrosis, even atrophy after orchidopexy in patients with the history shorter than 10 hour. Sessions et al. (14) reported testicular atrophy during follow-up in $27 \%$ of patients after orchidopexy within 4 hours of onset of symptoms. In our study $63 \%$ of TT of which $47 \%$ lasted shorter than 12 hour, and 16\% longer than 12 hour were salvaged after second look exploration. Barbalias and Liatsikos (16) have reported testicular salvage more than 24 hour after onset of symptoms. Kaye et al. (17) reported that in boys whose torsed testis was salvaged the pain was present for averagely 20 hours. Degree of torsion can be one of predictors in TT. Cimador et al. (10), and Mellick (13) found that there is no significant difference in TT with rotation degree of 360 to those with more than 360 degree. In our patients series orchidopexy was performed in 20 cases which had more than 360 (360 - 540) degree and of which 16 were salvaged. Testis in high and transverse position, thickening of epididymis, retractile testis, and some times lack of the cremasteric reflex can cause TT $(2,13,18,19)$. Boettcher et al. (20) believe that a lack of the cremasteric reflux is another feature highly associated with TT, and was effective as a predictor in half of their patients. CDU is a consistently reliable tool for confirming the diagnosis of TT. Kalfa et al. (21) reported that twisted testis can be detected $96 \%$ by high-resolution ultrasonography, and 76\% by CDU (22). Preoperative CDU showed absent/weak flow in 50 cases in recent study. During surgical exploration, a deep incision of the tunica albuginea after detorsion to evaluate active bleeding within 10 minutes is mandatory. Arda and Ozyaylali (23) believe that this test is an effective means to assess objectively testicular viability during surgery. We performed this test in all cases, of which in orchidopexy group 20 cases were in grade I and 24 in grade II, but all orchidectomy groups were in grade III. Cimador et al. reported two cases of testicular atrophy in their follow-up within orchidopexy group, and we had only four cases within our follow-up. Korkes et al. (24) reported a higher number of TT during colder months, with a significant increase during winter. In recent study of 70 cases with TT, 31 (44\%) were in winter season, and 22 (31\%) patients referred during autumn season. Early diagnosis and exploration can prevent medico legal risks $(25,26)$.

TT requires emergency attention in order to optimize the testicular salvage rate. Imaging/radionuclide scanning should not be a cause of delay, also ultrasonography may produce false negative results, so early surgical exploration is mandatory, and second look exploration can be more effective in salvageability. Cold season, torsion degree higher than $360^{\circ}$ and a history longer than 12 hours were not specific signs of testicular non-viability. The school age group which is the most vulnerable one, should be informed about his topic to prevent testicular damage.

\section{Acknowledgements}

This study was financially supported by the office of the Vice Chancellor of Mofid Children's Hospital, Clinical Research Development Center (CRDC).

\section{References}

1. Sung EK, Setty BN, Castro-Aragon I. Sonography of the pediatric scrotum: emphasis on the Ts--torsion, trauma, and tumors. AJR Am J Roentgenol. 2012;198(5):996-1003.

2. Beni-Israel T, Goldman M, Bar Chaim S, Kozer E. Clinical predictors for testicular torsion as seen in the pediatric ED. Am J Emerg Med. 2010;28(7):786-9.

3. Erdogan A, Gunay EC, Gundogdu G, Avlan D. Testicular torsion in the left inguinal canal in a patient with inguinal hernia: a difficult case to diagnose. Mol Imaging Radionucl Ther. 2011;20(3):108-10.

4. Gupta A, Kumar A, Chandha B, Saroha M. Perinatal bilateral testicular torsion: A rare emergency with review of literature. Asian Journal of Medical Sciences. 2014;5(4):103-5.

5. Riaz-Ul-Haq M, Mahdi DE, Elhassan EU. Neonatal testicular torsion; a review article. Iran J Pediatr. 2012;22(3):281-9.

6. Shadgan B, Fareghi M, Stothers L, Macnab A, Kajbafzadeh AM. Diagnosis of testicular torsion using near infrared spectroscopy: A novel diagnostic approach. Can Urol Assoc J. 2014;8(3-4):E249-52.

7. Chmelnik M, Schenk JP, Hinz U, Holland-Cunz S, Gunther P. Testicular torsion: sonomorphological appearance as a predictor for testicular viability and outcome in neonates and children. Pediatr Surg Int. 2010;26(3):281-6.

8. Ota FS, Wiebe RA. Urogenital emergencies in boys; an evidencebased approach to sensitive issues. Pediatr Emerg Med Prac. 2004;1(4):1-20.

9. Wampler SM, Llanes M. Common scrotal and testicular problems. Prim Care. 2010;37(3):613-26.

10. Cimador M, DiPace MR, Castagnetti M, DeGrazia E. Predictors of testicular viability in testicular torsion. J Pediatr Urol. 2007;3(5):387-90.

11. Weerakkody Y, Gaillard F. Testicular torsion. Available from: http:radiopaedia.org/articles/testicular-torsion.

12. Boettcher M, Bergholz R, Krebs TF, Wenke K, Aronson DC. Clinical predictors of testicular torsion in children. Urology. 2012;79(3):670-4

13. Mellick LB. Torsion of the testicle: it is time to stop tossing the dice. Pediatr Emerg Care. 2012;28(1):80-6.

14. Sessions AE, Rabinowitz R, Hulbert WC, Goldstein MM, Mevorach RA. Testicular torsion: direction, degree, duration and disinformation.J Urol. 2003;169(2):663-5.

15. Jefferson RH, Perez LM, Joseph DB. Critical analysis of the clinical presentation of acute scrotum: a 9-year experience at a single institution. J Urol. 1997;158(3 Pt 2):1198-200. 


\section{Rouzrokh M et al.}

16. Barbalias GA, Liatsikos EN. Testicular torsion: can the testicle be saved one week later? Int Urol Nephrol.1999;31(2):247-51.

17. Kaye JD, Shapiro EY, Levitt SB, Friedman SC, Gitlin J, Freyle J, et al Parenchymal echo texture predicts testicular salvage after torsion: potential impact on the need for emergent exploration. $J$ Urol. 2008;180(4 Suppl):1733-6.

18. Waldert M, Klatte T, Schmidbauer J, Remzi M, Lackner J, Marberger M. Color Doppler sonography reliably identifies testicular torsion in boys. Urology. 2010;75(5):1170-4.

19. Nussbaum Blask AR, Rushton HG. Sonographic appearance of the epididymis in pediatric testicular torsion. AJR Am J Roentgenol. 2006;187(6):1627-35.

20. Boettcher M, Krebs T, Bergholz R, Wenke K, Aronson D, Reinshagen K. Clinical and sonographic features predict testicular torsion in children: a prospective study. BJU Int. 2013;112(8):1201-6.

21. Kalfa N, Veyrac C, Lopez M, Lopez C, Maurel A, Kaselas C, et al Multicenter assessment of ultrasound of the spermatic cord in children with acute scrotum. JUrol. 2007;177(1):297-301.

22. Irekpita E, Kesieme E, Kalu Q, Onuora V. Testicular Torsion: An Analysis Of Sixteen Consecutive Cases And A Review Of The Literature.J Clin Diagn Res . 2011;5(7):1413-5.

23. Arda IS, Ozyaylali I. Testicular tissue bleeding as an indicator of gonadal salvageability in testicular torsion surgery. BJU Int. 2001;87(1):89-92.

24. Korkes F, Cabral PR, Alves CD, Savioli ML, Pompeo AC. Testicular torsion and weather conditions: analysis of 21,289 cases in Brazil. Int Braz JUrol. 2012;38(2):222-8.

25. Perrotti M, Badger W, Prader S, Moran ME. Medical malpractice in urology, 1985 to 2004: 469 consecutive cases closed with indemnity payment. J Urol. 2006;176(5):2154-7.

26. Selbst SM, Friedman MJ, Singh SB. Epidemiology and etiology of malpractice lawsuits involving children in US emergency departments and urgent care centers. Pediatr Emerg Care. 2005;21(3):165-9. 